\title{
The contribution of foods to the dietary lipid profile of a Spanish population
}

\author{
Gemma Cucó $^{1, *}$, Joan Fernández-Ballart ${ }^{1}$, Carles Martí-Henneberg ${ }^{2} \dagger$ and Victoria Arija ${ }^{1}$ \\ 'Unitat de Medicina Preventiva i Salut Pública, Facultat de Medicina i Ciències de la Salut, Universitat Rovira i Virgili, \\ Sant Llorenç 21, E-43201 Reus, Spain: ${ }^{2}$ Unitat de Pediatria, Facultat de Medicina i Ciències de la Salut, Universitat \\ Rovira i Virgili, Reus, Spain
}

Submitted 19 November 2001: Accepted 11 March 2002

\begin{abstract}
Objective: To identify the food that has the greatest effect on the variation in the percentage of energy intake derived from fat and saturated fatty acids for the consumption of a Spanish population.

Design: A cross-sectional study of food consumption, using the 24-hour recall method for three non-consecutive days, one of which was a non-working day. Subjects were interviewed by trained interviewers in the subjects' homes. We used multiple linear regression for statistical analysis.

Setting: The citizens of Reus.

Subjects: One thousand and sixty subjects over five years old, randomly selected from the population census of Reus.

Results: In both sexes, the foods that mainly determine a high consumption of fat are oil and red meat while those that determine a lower consumption of fat are bread, savoury cereals and fruit. The foods that mainly determine a high consumption of saturated fatty acids are red meat and whole-fat dairy products while those that determine a low consumption are bread, savoury cereals and fruit.

Conclusions: In our population, feasible variations in the intake of some foods - less than one portion - would reduce the estimated percentage of energy intake derived from fat and saturated fatty acids by a quantity considered important for cardiovascular disease prevention. The periodic identification and quantification of the food that most affects the dietary fat profile will help in drawing up dietary guidelines with more reasonable strategies for consuming a healthier diet and decreasing the risk of developing nutritional disorders.
\end{abstract}

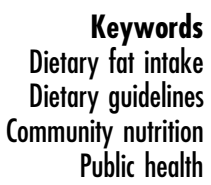

Over the last decades, improvements in the socioeconomic level of Western society have meant that the current dietary pattern is predominantly rich in animal products - that is to say, high in fat and saturated fatty acids (SFA) - and poor in vegetable products. The habitual consumption of this dietary pattern has been related to an increase in the risk of developing such chronic illnesses as cardiovascular disorders, obesity and cancer ${ }^{1,2}$.

As a result of these changes, the main aims of the dietary and nutritional policies of the developed countries have evolved from preventing nutritional deficiencies to preventing malnutrition due to the over-consumption of some nutrients ${ }^{3}$. Present nutritional goals aim to limit the consumption of fat to $30 \%$ of the daily energy intake and the consumption of SFA to less than $10 \%{ }^{4}$. Countries with a tradition of Mediterranean cuisine such as Spain, which consume large quantities of olive oil, have accepted that

tDeceased. fat consumption should be limited to $35 \%$ of the daily energy intake 5 .

Each population should develop its own strategies so that its subjects can fulfil their specific nutritional goals and have a healthy diet. These strategies should be based on dietary guidelines, which make recommendations about food and which are, therefore, a fundamental tool in nutritional education. Each society combines food groups according to cultural, geographic and socio-economic factors and, in this way, form several characteristic patterns of food consumption. Before drawing up dietary guidelines that attempt to adjust the nutritional contribution, it is necessary to know which dietary patterns and/ or foods contribute most to the intake of target nutrients in each society or country ${ }^{6}$.

In a previous study, we analysed and described various consumption patterns in our population. We identified those food groups that contribute towards a diet that resembles the diet recommended by the dietary 
guidelines ${ }^{7}$. However, if we are to offer dietary advice that is relevant to the needs of our population, we must identify the foods that contribute to the increase or decrease of the fat content in our diet as a whole. The fat content of the overall diet of an individual depends on the quantity of fat in the food consumed, on the frequency of consumption of these foods and on the overall diet. For example, two individuals who consume the same quantity of fat may have different percentages of fat- and SFAderived energy intake, depending on the other food groups they consume. We believe that identifying the foods that most affect the fat content of the diet (whether they contain fat or not) can help in the process of drawing up more effective dietary guidelines, with nutritional education strategies more directed at the needs of our population.

The aim of this study was to identify those foods that have the greatest effect on the variation in the percentage of energy intake supplied by lipids and SFA in the consumption of a Spanish population.

\section{Material and methods}

In 1993, we carried out a cross-sectional study of food consumption in Reus, a Spanish Mediterranean city of approximately 91000 inhabitants. We studied 1167 subjects randomly selected from the population census of Reus. The sample included subjects who were representative of all ages, sexes and socio-economic and educational levels ${ }^{8,9}$. In this paper, we study 1060 individuals from this sample, all older than 5 years.

Food intake was assessed with the 24-hour recall method on three non-consecutive days, one of which was not a working day ${ }^{10,11}$. For a better assessment of the quantity of food ingested, an extensive file of photographs was used which showed different portions of different foods and a standardised table to value the edible part of the food. The subjects were interviewed by trained interviewers in the subjects' homes and in the presence of the family member in charge of preparing and cooking the food. The dietary information was collected throughout the year in order to take into account the seasonal variability in food consumption.

The INSERM-ISTNA food composition table was used $^{12}$. Foods were divided into the following groups: red meat, poultry and game, cold cured meats (including chorizo, salami, etc.), eggs, white fish, blue fish, reducedfat milk and yoghurt, whole-fat milk and yoghurt, cheese, sweet cereals (breakfast cereals, cakes, biscuits), savoury cereals (such as pasta and rice but not bread), bread, oils, butter, green vegetables (all vegetables except for root vegetables and tubers, which are grouped separately), fruit, dried pulses, root vegetables and tubers, sugars, wine and liquors. The number of portions of each food group consumed by the population was calculated. To do so, the grams consumed of each food group were divided by the size of the standard portion for different age groups (Table 1). These standard portions have already been used

Table 1 Size of standard portions per age group and mean number of standard portions consumed per day

\begin{tabular}{|c|c|c|c|c|c|c|c|c|c|c|c|}
\hline \multirow[b]{3}{*}{ Food group } & \multicolumn{5}{|c|}{ Standard portions (g) } & \multicolumn{6}{|c|}{ Number of standard portions } \\
\hline & \multicolumn{5}{|c|}{ Age (years) } & \multicolumn{3}{|c|}{ Men } & \multicolumn{3}{|c|}{ Women } \\
\hline & $5-6$ & $7-12$ & $13-18$ & $19-59$ & $\geq 60$ & $\mathrm{P}_{25}{ }^{*}$ & $P_{50}$ & $\mathrm{P}_{75}$ & $\mathrm{P}_{25}$ & $P_{50}$ & $\mathrm{P}_{75}$ \\
\hline Red meat & 90 & 110 & 110 & 100 & 100 & 0.5 & 0.9 & 1.3 & 0.4 & 0.7 & 1.0 \\
\hline Poultry and game & 90 & 110 & 110 & 100 & 100 & 0.0 & 0.3 & 0.8 & 0.0 & 0.3 & 0.7 \\
\hline Cold cured meats & 40 & 50 & 60 & 50 & 50 & 0.0 & 0.3 & 0.6 & 0.0 & 0.1 & 0.3 \\
\hline Eggs & 50 & 100 & 100 & 100 & 50 & 0.1 & 0.3 & 0.5 & 0.0 & 0.2 & 0.3 \\
\hline White fish & 100 & 120 & 130 & 120 & 100 & 0.0 & 0.0 & 0.3 & 0.0 & 0.0 & 0.3 \\
\hline Blue fish & 100 & 120 & 130 & 120 & 100 & 0.0 & 0.1 & 0.3 & 0.0 & 0.1 & 0.3 \\
\hline Reduced-fat milk and yoghurt & 175 & 225 & 225 & 200 & 200 & 0.0 & 0.0 & 0.0 & 0.0 & 0.0 & 0.6 \\
\hline Whole-fat milk and yoghurt & 175 & 225 & 225 & 200 & 200 & 0.4 & 1.0 & 1.7 & 0.2 & 1.0 & 1.5 \\
\hline Cheese & 30 & 40 & 50 & 50 & 50 & 0.0 & 0.2 & 0.6 & 0.0 & 0.1 & 0.5 \\
\hline Sweet cereals & 40 & 50 & 80 & 60 & 50 & 0.0 & 0.5 & 0.9 & 0.1 & 0.5 & 0.9 \\
\hline Savoury cereals $\dagger$ & 40 & 50 & 70 & 70 & 40 & 0.2 & 0.5 & 0.9 & 0.2 & 0.5 & 0.8 \\
\hline Bread & 40 & 50 & 80 & 65 & 50 & 1.2 & 1.9 & 2.6 & 0.7 & 1.2 & 1.8 \\
\hline Oil & 15 & 25 & 25 & 25 & 25 & 1.1 & 1.6 & 2.1 & 0.9 & 1.3 & 1.7 \\
\hline Butter & 15 & 25 & 25 & 25 & 25 & 0.0 & 0.0 & 0.0 & 0.0 & 0.0 & 0.1 \\
\hline Green vegetables $\ddagger$ & 125 & 200 & 250 & 225 & 150 & 0.2 & 0.4 & 0.6 & 0.2 & 0.4 & 0.6 \\
\hline Fruit & 115 & 130 & 130 & 130 & 130 & 0.9 & 1.5 & 2.4 & 1.0 & 1.6 & 2.3 \\
\hline Dried pulses & 40 & 40 & 60 & 60 & 40 & 0.0 & 0.1 & 0.4 & 0.0 & 0.0 & 0.3 \\
\hline Root vegetables and tubers & 190 & 250 & 400 & 350 & 200 & 0.1 & 0.2 & 0.3 & 0.1 & 0.1 & 0.2 \\
\hline Sugars & 15 & 15 & 15 & 15 & 15 & 0.8 & 1.6 & 3.1 & 0.6 & 1.3 & 2.7 \\
\hline Wine & 100 & 100 & 100 & 100 & 100 & 0.0 & 0.0 & 1.3 & 0.0 & 0.0 & 0.2 \\
\hline Liquors & 50 & 50 & 50 & 50 & 50 & 0.0 & 0.0 & 0.3 & 0.0 & 0.0 & 0.0 \\
\hline
\end{tabular}

Number of cases: men, 520; women, 540.

${ }^{*} P_{n}-n$th percentile.

† All cereals with the exception of breakfast cereals, biscuits and pastries, which are classified as sweet cereals.

$\ddagger$ All vegetables with the exception of root vegetables and tubers, which are classified separately. 
in previous studies in our population ${ }^{7}$. The percentage of fat- and SFA-derived energy intake was calculated.

The following models of multiple linear regression were applied.

- First model. We used two multiple linear regressions to calculate the variation in the percentage of fat- and SFAderived energy intake for a standard portion (SP) of food. This model predicts the change in the percentage of (fat- and SFA-derived) energy intake when the consumption of a particular food group increases in an $\mathrm{SP}$. The following equation is used:

Predicted percentage of energy provided by the macronutrient

$$
\begin{aligned}
& =\alpha+\beta_{1} \text { red meat }+\beta_{2} \text { poultry and game } \\
& +\beta_{3} \text { cold cured meats }+\beta_{4} \text { eggs } \\
& +\beta_{5} \text { white fish }+\beta_{6} \text { blue fish } \\
& +\beta_{7} \text { reduced-fat milk and yoghurts } \\
& +\beta_{8} \text { whole-fat milk and yoghurts } \\
& +\beta_{9} \text { cheese }+\beta_{10} \text { sweet cereals } \\
& +\beta_{11} \text { savoury cereals }+\beta_{12} \text { bread }+\beta_{13} \text { oils } \\
& +\beta_{14} \text { butter }+\beta_{15} \text { vegetables }+\beta_{16} \text { fruit } \\
& +\beta_{17} \text { dried pulses } \\
& +\beta_{18} \text { root vegetables and tubers }+\beta_{19} \text { sugars } \\
& +\beta_{20} \text { wine }+\beta_{21} \text { liquors. }
\end{aligned}
$$

- Second model. To determine the effect of an individual's average food consumption on the percentages of (fatand SFA-derived) energy intake we carried out two multiple linear regressions. However, instead of using $\mathrm{SP}$ as the independent variable, as in the first model, we used the portion relative to the consumption of the population (RP), which is calculated for each individual as follows:

$$
\mathrm{RP}=\frac{\begin{array}{c}
\text { number of SPs of a food consumed } \\
\text { by a subject }
\end{array}}{\begin{array}{c}
\text { average number of SPs of that food } \\
\text { consumed by the population }
\end{array}} .
$$

This model was applied to the same subjects to simulate the effect of a variation in intake in the group of cereals.

We made sure that all of the multiple regressions were applied in conditions that ensured a suitable fit. These conditions were explored using relevant residual analyses. The data were analysed with the software SPSS 10.0 for
Windows. In all statistical tests we used the level of significance $P<0.05$ for bilateral contrasts.

\section{Results}

Table 2 shows how the percentage of fat-derived energy intake varies per SP of food consumed in both sexes. Oil is the food that is associated with the greatest percentage of fat-derived energy intake per SP consumed, in both men and women (5.7\% and 6.4\%, respectively). Food such as butter, cold cured meats, red meat, cheese and eggs are also related to high percentages of fat-derived energy intake (between 1.4\% and 5\%). In both sexes the consumption of an SP of reduced-fat milk and yoghurt, savoury cereals, dried pulses, bread and fruit provides a lower percentage of fat-derived energy intake (between $-1.3 \%$ and $-4.2 \%$ ). The consumption of an SP of the other foods varies this percentage to a lesser extent.

Table 3 shows how the percentage of SFA-derived energy intake varies for each SP of food consumed in both sexes. The consumption of an SP of butter provides the greatest percentage of SFA-derived energy intake in both men and women (3.9\% and 4.8\%, respectively). The consumption of an SP of cheese, red meat, cold cured meats, and whole-fat milk and yoghurt is also related to a greater percentage of this macronutrient (between 1.1\% and $2.7 \%$ ). Savoury cereals, bread and dried pulses are associated with lower percentages of SFA-derived energy intake (between $-1 \%$ and $-1.6 \%$ ).

Figure 1 shows, for both sexes, how changes in the RP affect the percentage of fat-derived energy intake in the diet of our population. The food group that is associated with the highest percentage of fat-derived energy intake is oils ( $9.4 \%$ and $8.7 \%$ in men and women, respectively). Red meat also has a considerable influence (approximately $2 \%$ ) but cold cured meats are less important. Bread is the food that contributes most to decreasing the percentage of fat $(-4 \%$ and $-5 \%$ in men and women, respectively) in this population, followed by savoury cereals and fruit (between $-2 \%$ and $-3 \%$ ).

Figure 2 shows the effect that changes in RP have on the percentage of SFA-derived energy intake in the diet of our population, in both sexes. Red meat and whole-fat dairy products (milk and yoghurt and cheese) are the foods that are related to the greatest percentages of SFA-derived energy intake (between $0.8 \%$ and 1.3\%). Butter and cold cured meats, on the other hand, contribute very little. Savoury cereals, bread and fruit are the food groups that provide the lowest percentages of SFA-derived energy intake (between $-0.8 \%$ and $-1.9 \%$ ).

Because these results show that cereals are very important for improving the dietary fat profile of our population, we used the second multiple regression model to simulate the effect of the following dietary change: the whole population changes its consumption of sweet cereals for savoury cereals and, from 13 years old 
Table 2 Change in the percentage of fat-derived energy intake per intake of one standard portion, for both sexes

\begin{tabular}{|c|c|c|c|c|c|c|}
\hline \multirow[b]{4}{*}{ Food group } & \multicolumn{6}{|c|}{$\%$ Fat-derived energy intake } \\
\hline & \multicolumn{3}{|c|}{ Men } & \multicolumn{3}{|c|}{ Women } \\
\hline & \multirow{2}{*}{$\begin{array}{l}\text { Regression } \\
\text { coefficient }\end{array}$} & \multicolumn{2}{|c|}{$95 \% \mathrm{Cl}$} & \multirow{2}{*}{$\begin{array}{l}\text { Regression } \\
\text { coefficient }\end{array}$} & \multicolumn{2}{|c|}{$95 \% \mathrm{Cl}$} \\
\hline & & LL & UL & & LL & UL \\
\hline Red meat & $2.1^{\star \star \star}$ & 1.7 & 2.6 & $2.5^{\star \star \star}$ & 1.9 & 3.1 \\
\hline Poultry and game & -0.1 & -0.6 & 0.4 & -0.2 & -0.8 & 0.5 \\
\hline Cold cured meats & $3.2^{\star \star \star}$ & 2.7 & 3.7 & $3.4^{\star \star *}$ & 2.5 & 4.2 \\
\hline Eggs & $1.4^{\star \star \star}$ & 0.5 & 2.3 & $2.1^{\star \star}$ & 0.8 & 3.3 \\
\hline White fish & 0.6 & -0.3 & 1.5 & -0.2 & -1.4 & 0.9 \\
\hline Blue fish & -0.1 & -1.0 & 0.8 & 0.3 & -0.7 & 1.4 \\
\hline Reduced-fat milk and yoghurt & $-2.2^{\star \star \star}$ & -2.8 & -1.5 & $-2.0^{\star \star \star}$ & -2.5 & -1.5 \\
\hline Whole-fat milk and yoghurt & -0.1 & -0.5 & 0.2 & -0.2 & -0.6 & 0.2 \\
\hline Cheese & $2.0^{\star \star \star}$ & 1.5 & 2.5 & $2.4^{\star \star \star}$ & 1.8 & 3.0 \\
\hline Sweet cereals & $-0.9^{\star \star \star}$ & -1.0 & -0.8 & $-1.1^{\star \star \star}$ & -1.6 & -0.7 \\
\hline Savoury cereals $\dagger$ & $-3.8^{\star * \star}$ & -4.3 & -3.3 & $-4.0^{\star \star \star}$ & -4.6 & -3.4 \\
\hline Bread & $-2.5^{\star \star \star}$ & -2.7 & -2.2 & $-3.0^{\star \star \star}$ & -3.3 & -2.6 \\
\hline Oil & $5.7^{\star \star \star}$ & 5.2 & 6.1 & $6.4^{\star \star \star}$ & 5.9 & 6.9 \\
\hline Butter & $3.5^{\star \star \star}$ & 2.0 & 5.1 & $5.0^{\star \star \star}$ & 3.5 & 6.6 \\
\hline Green vegetables $\ddagger$ & 0.4 & -0.4 & 1.2 & 0.7 & -0.2 & 1.6 \\
\hline Fruit & $-1.3^{\star \star \star}$ & -1.5 & -1.1 & $-1.9^{\star \star \star}$ & -2.2 & -1.7 \\
\hline Dried pulses & $-3.1^{\star \star *}$ & -3.8 & -2.4 & $-4.2^{\star \star \star}$ & -5.1 & -3.4 \\
\hline Root vegetables and tubers & $-1.7^{\star}$ & -3.2 & -0.1 & -0.1 & -2.2 & 1.9 \\
\hline Sugars & $-0.9^{\star \star \star}$ & -1.0 & -0.8 & $-0.9^{\star \star *}$ & -1.1 & -0.8 \\
\hline Wine & $-0.3^{\star \star \star}$ & -0.5 & -0.1 & -0.2 & -0.6 & 0.2 \\
\hline Liquors & 0.3 & -0.8 & 1.2 & 1.0 & -1.4 & 3.5 \\
\hline Regression constant, $\alpha$ & $41.9^{\star \star \star}$ & 40.8 & 43.0 & $42.8^{\star \star \star}$ & 41.7 & 44.0 \\
\hline $\mathrm{c} R^{2} \times 100$ & 80.5 & & & 78.3 & & \\
\hline$F_{21,498} / F_{21,518} \S$ & $103.0^{\star \star \star}$ & & & $93.5^{\star \star \star}$ & & \\
\hline
\end{tabular}

Number of cases: men, 520; women, 540. Cl - confidence interval; LL - lower limit; UL - upper limit; $\mathrm{c} R^{2}-\mathrm{corrected}$ square of the multiple correlation coefficient.

†All cereals with the exception of breakfast cereals, biscuits and pastries, which are classified as sweet cereals.

$\ddagger$ All vegetables with the exception of root vegetables and tubers, which are classified separately.

$\S F$ of Snedecor from analysis of variance of the multiple linear regression, in men/in women.

${ }^{\star}, P<0.05,{ }^{\star *}, P<0.01 ;{ }^{* \star *}, P<0.001$.

onwards, subjects increase their consumption of cereals by an SP of bread per day. We do not suggest that subjects younger than 13 years old should increase their consumption of bread by an SP because their average consumption of cereals is close to what is recommended and any increase would mean consuming more than recommended. Neither do we make different recommendations for both sexes because the consumption in both age groups is similar between sexes. This simulation shows that in those younger than 13 years old the observed percentage of fat-derived energy intake (40.6\%) would decrease to $37.7 \%$ and the observed percentage of SFA-derived energy intake (14.3\%) would decrease to $13.7 \%$. In those subjects who are 13 years old or above, the observed percentage of fat-derived energy intake (42.5\%) would decrease to $38.3 \%$ and the observed percentage of SFA-derived energy intake (13.7\%) would decrease to $12.2 \%$.

\section{Discussion}

\section{Method}

Food-based dietary guidelines are valid strategies for carrying out appropriate dietary and nutritional policies that can be easily understood by the population. According to the Food and Agriculture Organization/
World Health Organization $(\mathrm{FAO} / \mathrm{WHO})^{6}$, in order to establish food-based nutritional guidelines, target foods must first be identified on which the subsequent recommendations of the dietary guidelines will be based. Because our nutritional goals recommend a decrease in fat- and SFA-derived energy intakes, we were interested in identifying those foods that would most contribute to achieving these aims. We have described how these percentages vary throughout the population because dietary guidelines are usually directed at populations as a whole.

We used the 24-hour recall method to quantify food intake because it is the method of assessing retrospective dietary consumption that least interferes with the dietary habits of the subject interviewed ${ }^{13}$. So it reflects the spontaneous consumption of the population. Foods were classified into different groups according to their fat content, so the foods in each group were fairly homogeneous in this respect. In the analysis it was not necessary to adjust for age because different portions were considered for different age groups.

Dietary guidelines recommend that a number of portions be consumed from the different food groups. At present it is thought that dietary guidelines should make recommendations that are really achievable in the 
Table 3 Change in the percentage of SFA-derived energy intake per intake of one standard portion, for both sexes

\begin{tabular}{|c|c|c|c|c|c|c|}
\hline \multirow[b]{4}{*}{ Food group } & \multicolumn{6}{|c|}{$\%$ SFA-derived energy intake } \\
\hline & \multicolumn{3}{|c|}{ Men } & \multicolumn{3}{|c|}{ Women } \\
\hline & \multirow{2}{*}{$\begin{array}{l}\text { Regression } \\
\text { coefficient }\end{array}$} & \multicolumn{2}{|c|}{$95 \% \mathrm{Cl}$} & \multirow{2}{*}{$\begin{array}{c}\text { Regression } \\
\text { coefficient }\end{array}$} & \multicolumn{2}{|c|}{$95 \% \mathrm{Cl}$} \\
\hline & & LL & UL & & LL & UL \\
\hline Red meat & $1.3^{\star \star \star}$ & 1.1 & 1.6 & $1.5^{\star \star \star}$ & 1.1 & 1.9 \\
\hline Poultry and game & $0.6^{\star \star \star}$ & 0.3 & 0.8 & $0.4^{\star}$ & 0.1 & 0.8 \\
\hline Cold cured meats & $1.2^{\star \star \star}$ & 0.9 & 1.5 & $1.4^{\star \star \star}$ & 0.9 & 1.9 \\
\hline Eggs & $0.7^{\star \star}$ & 0.2 & 1.2 & $0.9^{\star \star}$ & 0.3 & 1.7 \\
\hline White fish & 0.0 & -0.5 & 0.4 & $-0.7^{\star}$ & -1.4 & -0.1 \\
\hline Blue fish & $0.7^{\star \star}$ & 0.2 & 1.2 & $0.6^{\star}$ & 0.0 & 1.2 \\
\hline Reduced-fat milk and yoghurt & $-0.7^{\star \star *}$ & -1.1 & -0.4 & $-0.8^{\star \star \star}$ & -1.1 & -0.5 \\
\hline Whole-fat milk and yoghurt & $1.1^{\star * *}$ & 0.9 & 1.2 & $1.1^{\star \star *}$ & 0.9 & 1.3 \\
\hline Cheese & $2.2^{\star \star}$ & 2.0 & 2.5 & $2.7^{\star \star \star}$ & 2.3 & 3.0 \\
\hline Sweet cereals & $-0.3^{\star *}$ & -0.5 & -0.1 & -0.1 & -0.3 & -0.1 \\
\hline Savoury cereals $\dagger$ & $-1.1^{\star \star \star}$ & -1.4 & -0.8 & $-1.3^{\star \star \star}$ & -1.7 & -1.0 \\
\hline Bread & $-0.9^{\star * *}$ & -1.1 & -0.8 & $-1.0^{\star \star \star}$ & -1.2 & -0.8 \\
\hline Oil & 0.1 & -0.1 & 0.3 & 0.1 & -0.2 & 0.4 \\
\hline Butter & $3.9^{\star \star *}$ & 3.1 & 4.8 & $4.8^{\star \star \star}$ & 4.0 & 5.7 \\
\hline Green vegetables $\ddagger$ & -0.2 & -0.4 & 0.3 & 0.0 & -0.5 & 0.5 \\
\hline Fruit & $-0.5^{\star \star}$ & -0.6 & -0.4 & $-0.8^{\star \star \star}$ & -1.0 & -0.6 \\
\hline Dried pulses & $-1.1^{\star \star *}$ & -1.4 & -0.7 & $-1.6^{\star \star \star}$ & -2.1 & -1.1 \\
\hline Root vegetables and tubers & $-1.0^{\star}$ & -1.8 & -0.2 & -0.2 & -1.4 & 0.9 \\
\hline Sugars & $-0.2^{\star \star \star}$ & -0.3 & -0.2 & $-0.2^{\star \star \star}$ & -0.3 & -0.1 \\
\hline Wine & $-0.1^{\star \star}$ & -0.2 & -0.0 & -0.0 & -0.2 & 0.3 \\
\hline Liquors & 0.0 & -0.5 & 0.6 & 0.6 & -0.8 & 2.0 \\
\hline Regression constant, $\alpha$ & $13.7^{* \star *}$ & 13.1 & 14.3 & $14.3^{* * *}$ & 13.6 & 14.9 \\
\hline$c R^{2} \times 100$ & 69.2 & & & 66.4 & & \\
\hline$F_{21,498} / F_{21,518} \S$ & $56.6^{* \star *}$ & & & $51.6^{* * *}$ & & \\
\hline
\end{tabular}

Number of cases: men, 520; women, 540. Cl - confidence interval; LL - lower limit; UL - upper limit; $c R^{2}-$ corrected square of the multiple correlation coefficient; SFA - saturated fatty acids.

†All cereals with the exception of breakfast cereals, biscuits and pastries, which are classified as sweet cereals.

$\ddagger$ All vegetables with the exception of root vegetables and tubers, which are classified separately.

$\S F$ of Snedecor from analysis of variance of the multiple linear regression, in men/in women.

${ }^{*}, P<0.05 ;{ }^{* \star}, P<0.01 ;{ }^{* *}, P<0.001$.

socio-economic context of the population they are aimed $a^{6}$. In the first model (Tables 2 and 3) we have described the effect that consuming one portion of an SP from each food group has on the dietary fat profile of the subjects' diet. The habitual diet of the subjects contains foods that are consumed at a very different frequency than one portion per day, so in the second model (Figs 1 and 2) we have attempted to analyse how changes in RP affect the fat profile. We are aware that this change may be very important quantitatively. Even so, we believe that this second model better reflects the real consumption of the population and it also enables the different food groups to be compared.

\section{Variation in energy intake provided by fat}

Oil is the food that provides the highest percentage of fatderived energy intake in the diet of our population; an RP of oil increases the fat-derived energy intake by approximately 9\% (Fig. 1). Animal fats such as butter, on the other hand, have little effect on this percentage (Fig. 1) because consumption is sporadic (Table 1). Our population still conserves one of the fundamental characteristics of the Mediterranean diet: that is to say, olive oil is the main source of dietary fat ${ }^{9,14}$ and it substitutes other animal fats, such as butter, that are widely used in other Western societies ${ }^{15,16}$. This is important because it is believed that the lower incidence of cardiovascular diseases in Mediterranean countries may be partly due to the fact that the consumption of monounsaturated fatty acids, provided by olive oil, is higher than the consumption of $\mathrm{SFA}^{17}$. The regular consumption of olive oil in the diet, instead of other sources of saturated fat, improves the profile of lipoprotein in the blood ${ }^{18}$ and protects lipoproteins from oxidation ${ }^{19}$, which is a mechanism that is involved in the pathogenesis of atherosclerosis.

In our population ${ }^{7}$ and also in others ${ }^{20-27}$, a meat-rich diet was related to a greater total intake of fat. Nevertheless, it is clear that not all meat types affect the fat-derived energy intake to the same extent. A high consumption of red meat has been related to a greater risk of developing cancer of the colon, breast and prostate ${ }^{28}$ and cardiovascular diseases ${ }^{15,29}$. In our population, we observe that the consumption of one SP of red meat and cold cured meats leads to notably higher percentages of fat-derived energy intake (Table 2) whereas the consumption of poultry and game has hardly any effect. In the context of our habitual diet, the effect of consuming an RP of red meat is more important (approximately 2\%) than the effect of consuming cold cured meats (Fig. 1), unlike what 


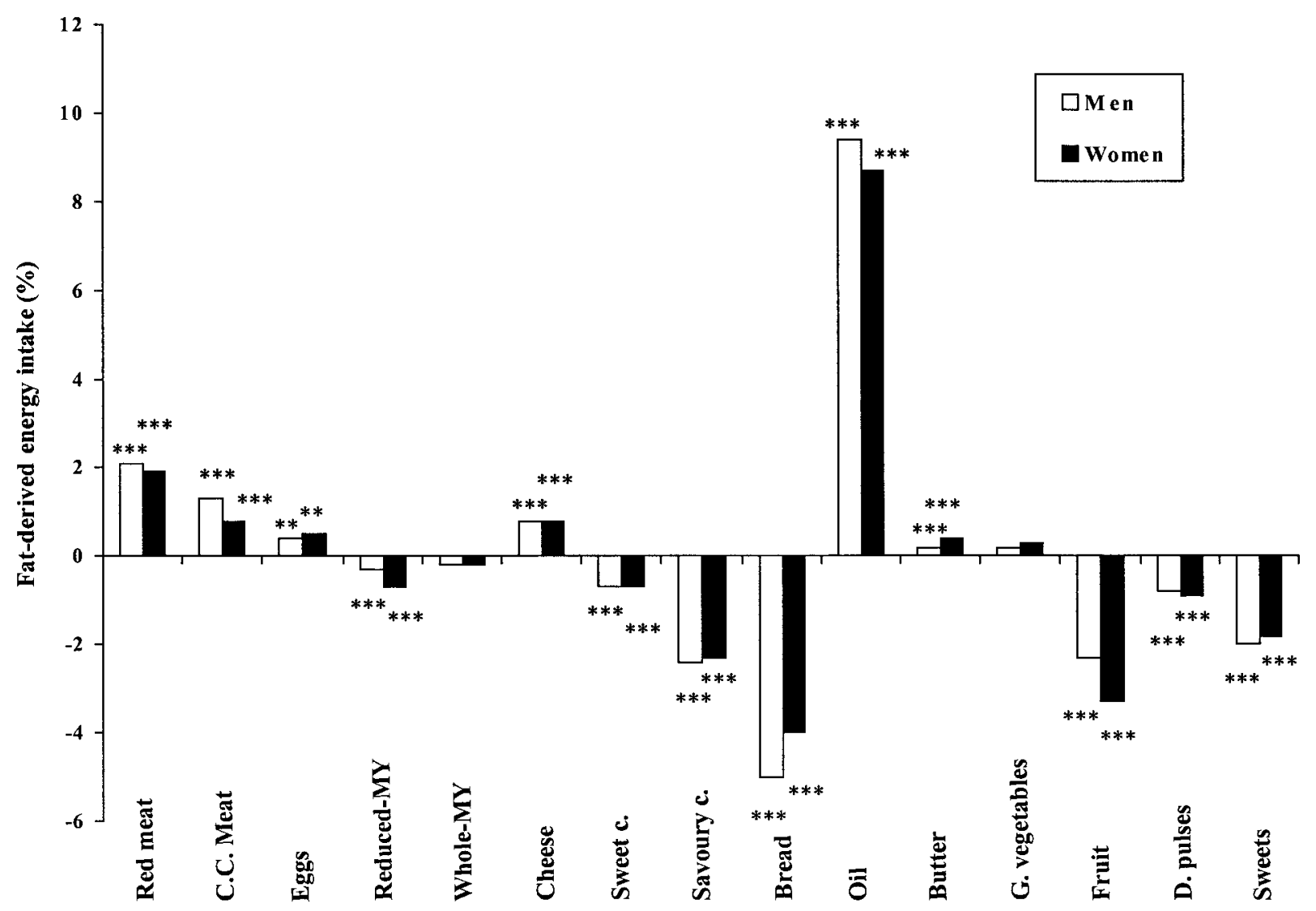

Fig. 1 Change in the percentage of fat-derived energy intake per relative portion of the population intake. Number of cases: men, 520; women, 540. Men: $F_{21.498}=103.0, P<0.001$; corrected $R^{2}=0.805$; constant of regression $=41.9$. Women: $F_{21.518}=93.5, P<0.001$; corrected $R^{2}=0.783$; constant of regression $=42.8$. C.C.Meat - cold cured meat; Reduced-MY - reduced-fat milk and yoghurt; WholeMY - whole-fat milk and yoghurt; Sweet c. - sweet cereals; Savoury c. - other cereals with the exception of bread; G. vegetables green vegetables (all vegetables with the exception of root vegetables and tubers, which are classified separately); D. pulses - dried pulses. *, $P<0.05 ;{ }^{* *}, P<0.01 ;{ }^{* * *}, P<0.001$

happens in other populations (e.g. Germany) ${ }^{30}$. We have identified a food, red meat, that is consumed in excess and helps to increase fat-derived energy intake. In our population, we have observed a considerable variation in mean meat consumption between people classified according to tertiles of meat consumption: first tertile $91 \mathrm{~g} \mathrm{day}^{-1}$, second tertile $-143 \mathrm{gday}^{-1}$, third tertile 226 g day $^{-1}$. Those people whose consumption was below the first tertile have a percentage of fat-derived energy intake that is approximately 3.5\% lower than people whose consumption is above the third tertile ${ }^{7}$. We believe that with appropriate nutritional education it would be feasible for those people whose consumption is high to reduce it, for example, by half. Therefore, their meat consumption would be similar to that of the people in the low tertile.

Cereals are the foods that are related to lower percentages of fat-derived energy intake in the diet of our population. This notable improvement in the dietary lipid profile is due to the fact that a diet rich in carbohydrates means that the population does not habitually consume other elements that are richer in fats $^{7}$. The effect of consuming an SP of savoury cereals (pasta and rice) on the percentage of fat-derived energy intake is greater than that of an SP of bread (Table 2). However, in our habitual diet, bread is consumed more than savoury cereals (Table 1) and, therefore, the effect of an RP of bread is greater (Fig. 1). Because sweet cereals are not consumed very frequently (less than one portion a day), they are not associated with a greater percentage of fat-derived energy intake even though they are a dietary source of invisible fat. In other Western populations, such as North America, the consumption of invisible fat is becoming increasingly important in the overall fat intake $^{31}$. In the simulation that we carried out, we observed that small dietary changes could lead to notable improvements in the fat profile. If children below 13 years of age were to replace the amount of sweet cereals they habitually consume (median: 0.5 portions) by savoury cereals such as pasta and rice, they would reduce fatderived energy intake by 2.9 points and SFA-derived energy intake by 0.6 points. If people above 13 years of age were to do the same and also consume one more SP of bread per day, the reduction in the fat and SFA percentages would be 4.2 points and 1.5 points, respectively. It would probably be easier for the population to replace one food by another food from the same group. What is more, we believe that an increase 


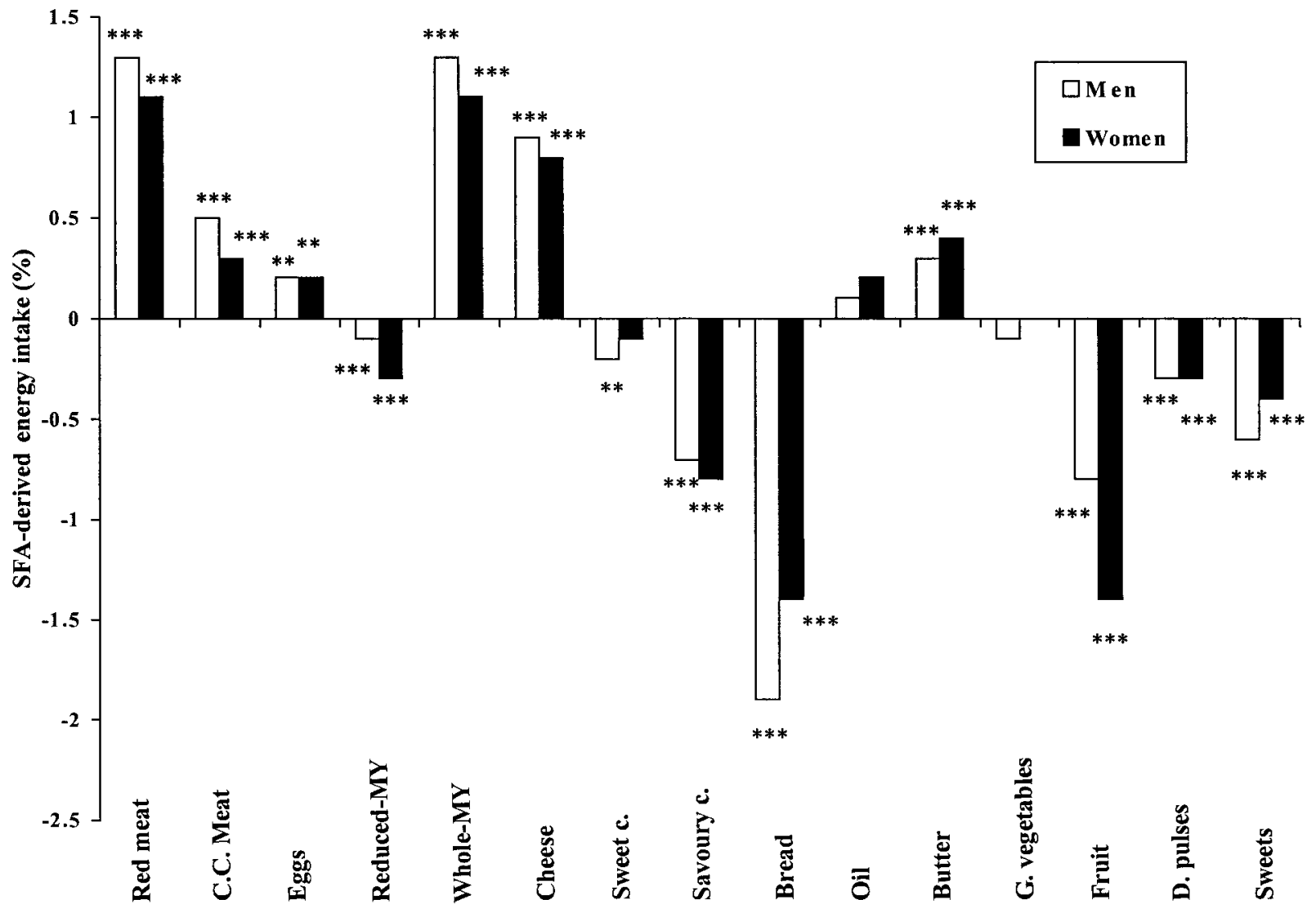

Fig. 2 Change in the percentage of SFA-derived energy intake per relative portion of the population intake. Number of cases: men, 520; women, 540. Men: $F_{21.498}=56.6, P<0.001$; corrected $R^{2}=0.692$; constant of regression $=13.7$. Women: $F_{21.518}=51.6, P<0.001$; corrected $R^{2}=0.664$; constant of regression $=14.3$. C.C.Meat - cold cured meat; Reduced-MY - reduced-fat milk and yoghurt; WholeMY - whole-fat milk and yoghurt; Sweet c. - sweet cereals; Savoury c. - other cereals with the exception of bread; G. vegetables green vegetables (all vegetables with the exception of root vegetables and tubers, which are classified separately); D. pulses - dried pulses. ${ }^{*}, P<0.05 ;{ }^{* *}, P<0.01 ;{ }^{* \star *}, P<0.001$

of one SP of bread a day for people older than 13 would not interfere with their dietary habits because it could be easily introduced: for example, this quantity of plain bread could be divided between lunch and dinner. We believe that this dietary change would not alter the daily energy consumed because we know that when our population consumes more cereals, they consume fewer other foods, many of which are richer in fats ${ }^{7}$. Of course, the benefit on the fat profile would be even greater if the population were to consume what is recommended in the guidelines (five daily portions of cereals), but this would be much more difficult to apply. Our proposal is attainable in the context of our population and it is in line with the strategies that, according to the $\mathrm{FAO} / \mathrm{WHO}^{6}$, dietary guidelines should contain.

Scientific evidence relates a high consumption of fruit and vegetables, foods that are rich in phytochemical compounds and other natural antioxidants, to a protective effect against cardiovascular diseases and cancer ${ }^{32-34}$. In some populations, it has also been observed that a high consumption of fruit leads to a lower intake of fats $^{7,20,21,24-26,35-38}$. In our population, the consumption of fruit also helps to decrease the percentage of fat-derived energy intake. Even so, more than half of the population consumes fewer than the $2-3$ portions of fruit that are generally recommended (Table 1 ). If our community were to increase their fruit consumption by $25 \%$, the benefit to the percentage of lipid-derived energy intake would be considerable and, also, much of the population would comply with the recommendations of the guidelines. Contrary to what was expected, the consumption of vegetables in the diet of our population does not help to decrease the percentage of fat-derived energy intake: in fact, it increases it slightly. In our population ${ }^{7}$ and in others $^{36}$, it has been observed that a greater consumption of vegetables leads to a greater intake of added fats and fat-derived energy intake. If the whole of our population were to consume the two portions of vegetables that are generally recommended, and not the median 0.4 portions per day, the increase in the fat-derived percentage could be greater. In our community, the recommendation to consume more vegetables should be accompanied by appropriate nutritional and culinary education to prevent such a healthy proposal from leading to an increase in fat-derived energy intake.

In agreement with our previous results ${ }^{7}$, the consumption of whole-fat milk and yoghurt in our population increases SFA-derived energy intake but does not increase 
fat-derived energy intake, since the subjects who consume more milk and yoghurts do not consume other food that is even richer in fats. In other Western populations that consume more dairy products, the consumption of these foods does affect the fat-derived energy intake ${ }^{25,39}$.

Other foods such as reduced-fat dairy products and dried pulses are not consumed a great deal (Table 1) and so their contribution to the percentage of fat-derived energy intake is only slight (Fig. 1). It would be perfectly feasible for the population to double or even triple its consumption of these foods to substitute other fattier protein-rich foods and this would have a considerable positive effect on the percentage of fat-derived energy intake.

\section{Variation in the energy intake provided by SFA}

SFA-rich diets increase the risk of developing chronic illnesses such as cardiovascular diseases because they increase the low-density lipoprotein (LDL) cholesterol level ${ }^{40,41}$. We were interested in identifying the foods that most affect the percentage of SFA-derived energy intake in the diet of our population because the intake of saturated fat is considered to be the main dietary factor that determines the level of LDL cholesterol in the blood. Likewise, it is believed that reducing the consumption of saturated fat and increasing the consumption of polyunsaturated fat helps to decrease LDL cholesterol ${ }^{42}$.

Red meat and whole-fat dairy products (milk, yoghurt and cheese) are the foods that contribute most to increases in the percentage of SFA-derived energy intake in the diet of our population as a whole. On the other hand, in other Western countries such as Italy and Belgium, the main dietetic source of SFA is cheese ${ }^{43}$ or butter ${ }^{16}$, respectively. As our consumption of dairy products is below the two portions habitually recommended (Table 1 ), it would be necessary to encourage the consumption of reduced-fat dairy products (skimmed or semi-skimmed) in adults. For our population, a feasible recommendation would be that half of the dairy products consumed should be low in fat. This would lead to a considerable benefit as far as SFA is concerned. In the overall diet of our community, other foods high in SFA such as butter and cold cured meats have little effect on the increase in the percentage of SFA-derived energy intake because they are consumed little.

Bread, savoury cereals and fruit are the foods that are associated with the lowest percentages of SFA-derived energy intake in the diet of our population. The replacement of sweet cereals by savoury cereals mentioned above would reduce not only the percentage of fat-derived energy intake but also the SFA-derived energy intake for the cereal group.

The consumption of reduced dairy products and dried pulses has little effect on the percentages of SFA-derived energy intake because they are not consumed a great deal. As we have mentioned above, it would be possible for the population to double or triple its consumption and the impact on this percentage would therefore be much greater.

By identifying and quantifying the foods that most affect the variation of the fat and SFA intake in the diet of our population, we would be able to suggest more feasible strategies of food consumption. In the present consumption of our population, savoury cereals, bread and fruit are the foods that most improve the dietary fat profile, and red meat and whole dairy products are the foods that are most detrimental to it. In developed populations with a high fat intake such as ours, reductions in fat- and SFA-derived energy intake of about $7 \%$ of energy have been associated with a decrease in total cholesterol of $\cong 10 \%$. This in turn has been related to a reduction in cardiovascular mortality of $25-30 \%$ in subjects between 55 and 64 years old ${ }^{44}$. Our population could reduce its dietary fat profile by a similar percentage if individuals were to replace their consumption of sweet cereals by savoury cereals, consume one more SP of bread, reduce their consumption of red meat by half, ensure that half of the dairy products they consume were low in fat and increase their daily consumption of fruit by $25 \%$. These changes would help to make the diet a healthier one and reduce the risk of developing chronic diseases. We should bear in mind that eating habits are different in different populations, they change over time and changes in the consumption of one food can affect the consumption of other foods. Therefore, if dietary guidelines are to be effective tools for preventing nutritional diseases, the foods that most affect the overall dietary fat profile should be periodically verified.

\section{Acknowledgement}

This work was funded by the City Council of Reus.

\section{References}

1 World Health Organization (WHO). Diet, Nutrition, and the Prevention of Chronic Diseases. Technical Report Series No. 797. Geneva: WHO, 1990.

2 Pi-Sunyer X. Medical hazards of obesity. Ann. Intern. Med. 1993; 119: 655-60.

3 Drewnowski A, Popkin BM. The nutrition transition: new trends in the global diet. Nutr. Rev. 1997; 55: 31-43.

4 Eurodiet Core Report. Nutrition \& diet for healthy lifestyles in Europe: science \& policy implications. Public Health Nutr. 2001; 4(2A): 265-73.

5 Spanish Society of Community Nutrition (SENC). Guias Alimentarias Para la Población Española. Madrid: IM\&C, 2001.

6 World Health Organization (WHO). Preparation and Use of Food-based Dietary Guidelines. Report of a Joint FAO/WHO Consultation. Technical Report Series No. 880. Geneva: WHO, 1998.

7 Cucó G. Influencia de patrones alimentarios diferentes sobre el perfil nutricional de una población mediterránea. Doctorate thesis, Faculty of Medicine and Health Sciences, Universitat Rovira i Virgili, Reus, 1998.

8 Arija V, Salas-Salvadó J, Fernández-Ballart J, Cucó G, 
Martí-Henneberg C. Consumo, hábitos alimentarios y estado nutricional de la población de Reus (VIII). Evolución de la ingestión de energía y nutrientes entre 19831993 [Food consumption, habits and nutritional status of the population of Reus (VIII). Evolution of energy and nutrient intake from 1983 to 1993]. Med. Clin. (Barc.) 1996; 106: 45-50.

9 Arija V, Salas-Salvadó J, Fernández-Ballart J, Cucó G, MartíHenneberg C. Consumo, hábitos alimentarios y estado nutricional de la población de Reus (IX). Evolución del consumo de alimentos, de su participación en la ingestión de energÍa y nutrientes y su relación con el nivel socioeconómico y cultural entre 19831993 [Consumption, dietary habits and nutritional status of the Reus population (IX). Evolution of food consumption, energy and nutrient intake and relationship with the socioeconomic and cultural level, 1983-1993]. Med. Clin. (Barc.) 1996; 106: 174-9.

10 Beaton GH, Milner J, Corey P, McGuire V, Cousins M, Stewart E, de Ramos M, Hewitt D, Grambsch PV, Kassim N, Little JA. Sources of variance in 24-hour dietary recall data: implications for nutrition study design and interpretation. Am.J. Clin. Nutr. 1979; 32: 2546-59.

11 Pekkarinen M. Methodology in the collection of food consumption data. World Rev. Nutr. Diet. 1970; 12: 145-71.

12 Favier JC, Ireland-Ripert J, Toque C, Feinberg M. Répertoire General des Aliments. Table de Composition. Paris: TEC \& DOC Lavoiseier-INRA, 1997.

13 Buzzard M. 24-Hour dietary recall and food record methods. In: Willett W, ed. Nutritional Epidemiology. New York: Oxford University Press, 1998; 50-73.

14 Cucó G, Arija V, Martí-Henneberg C, Fernández-Ballart J. Food and nutritional profile of high energy density consumers in an adult Mediterranean population. Eur. J. Clin. Nutr. 2001; 55: 192-9.

15 Kushi LH, Lenart EB, Willett WC. Health implications of Mediterranean diets in light of contemporary knowledge. 2. Meat, wine, fats, and oils. Am.J. Clin. Nutr. 1995; 61(Suppl. 6): $1416 \mathrm{~S}-27 \mathrm{~S}$.

16 Staessen L, De Henauw S, De Bacquer D, De Backer G, Van Peteghem C. Fat sources in the Belgian diet. Ann. Nutr. Metab. 1998; 42: 138-50.

17 Keys A, Menotti A, Karvonen MJ, Aravanis C, Blackburn H, Buzina R, Djordjevic BS, Dontas AS, Fidanza F, Keys MH, Kromhout D, Nedeljkovic S, Punsar S, Seccareccia F, Toshima H. The diet and 15-year death rate in the Seven Countries Study. Am. J. Epidemiol. 1986; 124: 903-15.

18 Katan MB, Zock PL, Mensink RP. Dietary oils, serum lipoproteins and coronary heart disease. Am. J. Clin. Nutr. 1995; 61(Suppl. 6): 1368S-73S.

19 Fito M, Covas MI, Lamuela-Raventos RM, Vila J, Torrents L, de la Torre C, Marrugat J. Protective effect of olive oil and its phenolic compounds against low density lipoprotein oxidation. Lipids 2000; 35: 633-8.

20 Subar AF, Ziegler RG, Patterson BH, Ursin G, Graubard B. US dietary patterns associated with fat intake: The 1987 National Health Interview Survey. Am. J. Public Health 1994; 84: 359-66.

21 Osler M, Heitmann BL. Food patterns associated with intakes of fat, carbohydrate and dietary fibre in a cohort of Danish adults followed for six years. Eur. J. Clin. Nutr. 1997; 51: 354-61.

22 Blundell JE, Macdiarmid JI. Fat as a risk factor for overconsumption: satiation, satiety, and patterns of eating. J. Am. Diet. Assoc. 1997; 97(Suppl. 7): 63S-9S.

23 Ortega RM, Lopez-Sobaler AM, Requejo AM, Quintas ME, Gaspar MJ, Andres P, Navia B. The influence of meat consumption on dietary data, iron status and serum lipid parameters in young women. Int. J. Vitam. Nutr. Res. 1998; 68: $255-62$.
24 De Henauw S, De Backer G. Nutrient and food intakes in selected subgroups of Belgian adults. Br. J. Nutr. 1999; 81(Suppl. 2): 37S-42S.

25 Haraldsdóttir J. Dietary guidelines and patterns of intake in Denmark. Br.J. Nutr. 1999; 81(Suppl. 2): 43S-8S.

26 Serra-Majem LI, Ribas L, Ramon JM. Compliance with dietary guidelines in the Spanish population. Results from the Catalan Nutrition Survey. Br. J. Nutr. 1999; 81(Suppl. 2): $105 \mathrm{~S}-12 \mathrm{~S}$.

27 Volatier JL, Verger P. Recent national French food and nutrient intake data. Br.J. Nutr. 1999; 81(Suppl. 2): 57S-9S.

28 Bingham SA. High-meat diets and cancer risk. Proc. Nutr. Soc. 1999; 81: 243-8.

29 Hu FB, Stampfer MJ, Manson JE, Ascherio A, Colditz GA, Speizer FE, Hennekens CH, Willett WC. Dietary saturated fats and their food sources in relation to the risk of coronary heart disease in women. Am. J. Clin. Nutr. 1999; 70: 1001-8.

30 Winkler G, Döring A, Keil U. Trends in dietary sources of nutrients among middle-aged men in southern Germany. Results of the MONICA Project Augsburg: dietary surveys 1984/1985 and 1994/1995. Appetite 2000; 34: 37-45.

31 Popkin BM, Siega-Riz AM, Haines PS, Jahns L. Where's the fat?. Trends in U.S. diets 1965-1996. Prev. Med. 2001; 32: 245-54.

32 Willett WC. Diet and cancer: one view at the start of the millennium. Cancer Epidemiol. Biomark. Prev. 2001; 10: 3-8.

33 van't Veer P, Jansen M, Klerk M, Kok FJ. Fruits and vegetables in the prevention of cancer and cardiovascular disease. Public Health Nutr. 2000; 3: 103-7.

34 Craig WL. Phytochemicals: guardians of our health. J. Am. Diet. Assoc. 1997; 97(Suppl. 2): 199S-204S.

35 Hampl JS, Betts NM. Comparisons of dietary intake and sources of fat in low- and high-fat diets of 18- to 24-yearolds. J. Am. Diet. Assoc. 1995; 95: 893-7.

36 Krebs-Smith SM, Cleveland LE, Ballard-Barbash R, Cook DA, Kahle LL. Characterising food intake patterns of American adults. Am. J. Clin. Nutr. 1997; 65(Suppl. 4): 1264S-8S.

37 Becker W. Dietary guidelines and patterns of food and nutrient intake in Sweden. Br. J. Nutr. 1999; 81(Suppl. 2): 113S-7S.

38 Moschandreas J, Kafatos A. Food and nutrient intakes of Greek (Cretan) adults. Recent data for food-based dietary guidelines in Greece. Br.J. Nutr. 1999; 81(Suppl. 2): 71S-6S.

39 Flynn MAT, Kearney JM. An approach to the development of food-based dietary guidelines for Ireland. Br. J. Nutr. 1999; 81(Suppl. 2): $77 \mathrm{~S}-82 \mathrm{~S}$.

40 Kromhout D. Fatty acids, antioxidants, and coronary heart disease from an epidemiological perspective. Lipids 1999; 34(Suppl.): 27S-31S.

41 Grundy SM. The optimal ratio of fat-to-carbohydrate in the diet. Annu. Rev. Nutr. 1999; 19: 325-41.

42 Krauss RM, Eckel RH, Howard B, Appel LJ, Daniels SR, Deckelbaum RJ, Erdman JW Jr, Kris-Etherton P, Goldberg IJ, Kotchen TA, Lichtenstein AH, Mitch WE, Mullis R, Robinson K, Wylie-Rosett J, St Jeor S, Suttie J, Tribble DL, Bazzarre TL. AHA Dietary Guidelines: revision 2000: a statement for healthcare professionals from the Nutrition Committee of the American Heart Association. Circulation 2000; 102: 2284-99.

43 Favero A, Salvini S, Russo A, Parpinel M, Negri E, Decarli A, La Vechia C, Giacosa A, Franceschi S. Sources of macro- and micronutrients in Italian women: results from a food frequency questionnaire for cancer studies. Eur. J. Cancer Prev. 1997; 6: 277-87.

44 Law MR, Wald NJ, Thompson SG. By how much and quickly does reduction in serum cholesterol concentration lower risk of ischaemic heart disease? Br. Med. J. 1994; 308: 367-73. 